\title{
THE SKU BLA RITE IN IMPERIAL TIBETAN RELIGION
}

\author{
Nathan W. Hill
}

\begin{abstract}
Rolf Stein, Ariane Macdonald et d'autres savants considèrent le sku bla comme une divinité de la montagne. Stein voit ce culte comme une importation étrangère, tandis que Macdonald le considère comme un culte central de la religion impériale tibétaine. Après un réexamen des passages pertinents, l'auteur de cet article conclut que le sku bla n'est pas une divinité de la montagne et que la cérémonie sku bla n'est pas un emprunt extérieur au Tibet mais un élément central de l'idéologie de la royauté sacrée au sein de l'empire tibétain. Cette cérémonie créait un lien de vassalité entre le célébrant et la personne de l'empereur tibétain dans son rôle de souverain divinisé ; elle n'était pas célébrée par la cour royale elle-même, mais était plutôt pratiquée par les vassaux de l'empereur. Cette théorie explique l'absence du sku bla dans les Annales tibétaines (PT 1288, ITJ 750) et sa présence dans les Annales de la principauté de 'A zha (ITJ 1368), les envoyés du Phywa à Dmu (PT 126), l'inscription de Rkongpo et d'autres textes de Dunhuang tels que PT 1047 et PT 2204c. Cette théorie explique aussi l'utilisation du terme sku bla dans la paraphrase du Shangshu (PT 986) et les prières pour la fondation du monastère de De ga g.yu tshal (PT 16), mieux que l'influence chinoise proposé par Stein.
\end{abstract}

\section{Two views of the sku bla cult and its place in imperial Tibetan religion}

The sku bla ceremony is not mentioned in the Old Tibetan Annals (PT 1288, IOL Tib J 750, Or. 8210/187), ${ }^{1}$ but the celebration of this rite is recorded in the Annals of 'A zha Principality (IOL Tib J 1368), the analogous document for the vassal state of 'A zha. This anomalous distribution has led to two theories. Based on the occurrence of the term sku bla in the two geographically disparate texts, the Annals of 'A zha Principality (IOL Tib J 1368) and the Rkon-po Inscription, Ariane Macdonald concludes that "le culte des Sku-bla était donc largement répandu dans les couches supérieures de la société tibétaine ou tibétisée [the cult of the sku bla was thus largely spread across the upper strata of Tibetan or Tibetanized society]" (1971: 304). ${ }^{2}$ Macdonald sees mention of the sku bla in these two texts as sufficient evidence that this cult "avait une diffusion considérable au Tibet [had a considerable diffusion in Tibet]". ${ }^{3}$ Although the sku bla cult is not found in the Old Tibetan Annals (PT 1288, IOL Tib J 750), Macdonald believes "il est bien probable que des cérémonies analogues étaient également célébrées à la cour des rois du Tibet [it is likely that analogous ceremonies were also celebrated at the court of the Tibetan emperors]". Rolf Stein, however, sees the fact that her explanation gives no specific account for

1 All Dunhuang documents are cited according to their catalogue numbers at the Bibliothèque nationale de France ('Pelliot tibétain' abbreviated PT) and the British Library ('India Office Library Tib. J.' abbreviated IOL Tib J) and following the text given in Imaeda et al. (2007).

2 Ariane Macdonald, "Une lecture des P.T. 1286, 1287, 1038, 1047, et 1290. Essai sur la formation et l'emploi des mythes politiques dans la religion royale de Sron-bcan sgam-po," in Études tibétaines dédiées à la mémoire de Marcelle Lalou (Paris: Adrien Maisonneuve, 1971), 304.

Ibid.

4 Ibid. 
the absence of the sku bla cult in the Old Tibetan Annals as a weakness to her theory. ${ }^{5}$ The Annals of 'A zha Principality (IOL Tib J 1368) is generically similar to the Old Tibetan Annals (PT 1288, IOL Tib J 750), so the absence of the sku bla cult from the latter cannot be credited to a generic characteristic. ${ }^{6}$ Instead, the absence of the $s k u$ bla cult from the Old Tibetan Annals (PT 1288, IOL Tib J 750) implies its absence from central Tibetan statecraft. In contrast to Macdonald, Stein suggests that the $s k u$ bla cult was peripheral to Tibetan state religion, and is found in the Annals of ' $\mathrm{A}$ zha Principality (IOL Tib J 1368) because it is specifically characteristic of 'A zha ritual practice. ${ }^{7}$ Stein links this suggestion with evidence from the Tangshu 唐書 of the 'A zha (Tuyuhun 吐谷渾) practicing a cult of mountain deities (ji shan shen 祭山神), which he identifies with the sku bla, further suggesting that the cult may ultimately be of Chinese provenance. ${ }^{8}$ This Chinese connection also allows him to account for the mention of the sku bla in the Shangshu 尚書 paraphrase (PT 986), a Tibetan paraphrase of a Chinese text, and the Prayers for the foundation of De ga g.yu tshal monastery (PT 16), a document produced as part of the Sino-Tibetan treaty negotiations of 821-822. ${ }^{9}$

Stein's argument for a foreign origin of the $s k u$ bla faces various obstacles of its own. Most significantly, his account does not explain the presence of the sku bla in the wide variety of Tibetan texts in which it occurs, nor its apparent central relationship to the ideology of the Tibetan state. Stein acknowledges that the presence of the sku bla in the Envoys of Phywa to Dmu (PT 126) and the Rkon-po Inscription weighs against his theory, ${ }^{10}$ but makes no mention of the term sku bla in other texts (such as PT 1047, PT 1051, PT 2204c, IOL Tib J 734, IOL Tib J 738, IOL Tib J 739, IOL Tib J 751). A foreign origin of the $s k u$ bla also raises a linguistic question. The word sku bla is obviously Tibetan. If the cult is originally an 'A zha (Mongolic) or Chinese ritual practice it is necessary to identify the corresponding term in the source language and to account for why sku bla was chosen as a calque of this word in Tibetan. Macdonald's theory that the sku bla rite was central to imperial cult and

Rolf A. Stein, “Tibetica Antiqua I: Les deux vocabulaires des traductions indo-tibétaines et sinotibétaines dans les manuscrits Touen-Houang," Bulletin de l'École Française d'Extrême Orient 72 (1983): 205.

6 Géza Uray, "L'annalistique et la pratique bureaucratique au Tibet ancien," Journal Asiatique 263 (1975): 157-70, argues that different annalistic documents have different generic preoccupations. It must be admitted that variations within this genre could account for the absence of sku bla in the Old Tibetan Annals. Nonetheless, such an argument require a more thorough articulation of this genre than has been undertaken hitherto.

7 Stein, "Deux vocabulaires": 205

8 Ibid.

9 Ibid., 201-204. Michael Walter, "Analysis of PT016/IO751-Language and Culture of a Dunhuang document, part one," in Tibet after Empire Culture, Society and Religion between 850-1000, ed. Christoph Cüppers et al. (Lumbini: Lumbini International Research Institute 2013), 417ff., argues that this is a post-imperial document feigning imperial provenance. His argument is unconvincing. Most of the supposedly 'Classical Tibetan' vocabulary of the document is as easily explained as typical of Buddhist texts. Walter makes much of the 'incorrect' use of da drag in the text, but only a full study of da drag in Old Tibetan could establish 'correct' usage. Walter excludes men tog 'flower' as evidence for the text's early date because this pronunciation is reflected in some Tibetan dialects of our day (p. 435), but peripheral dialects are notorious for preserving archaisms (e.g. palatalized pronunciations of $m i$ 'person' in Amdo implying myi). Paradoxically Walter treats the word rje 'lord' in reference to the emperor as both impossible in Imperial documents (p. 430) and as "easily copied from inscriptions or Imperial-period documents" (p. 435) in the phrase Bod kyi lha btsan po myĭ rje lhas mdzad pa Khri Gstug Lde Brtsan.

10 Stein, "Tibetica Antiqua I": 204. 
identity accounts well for the attested occurrences of the term, but does not correctly predict its absence from the Old Tibetan Annals (PT 1288, IOL Tib J 750, Or.8210/187). Stein's theory that the sku bla cult was geographically and ideologically peripheral to the Old Tibetan Empire, correctly predicts its absence in the Old Tibetan Annals (PT 1288, IOL Tib J 750) and its presence in the Annals of 'A zha Principality (IOL Tib J 1368), and possibly also in the Shangshu paraphrase (PT 986) and the Prayers for the foundation of De ga g.yu tshal monastery (PT 16), but gives no account for the presence of the term in numerous other Old Tibetan texts. In sum, Macdonald's theory fails to explain one absence of the term; Stein's fails to explain numerous occurrences of the term. At face value Macdonald's hypothesis is therefore the more promising. Her theory would be perfected with an account for why the sku bla cult is not mentioned in the Old Tibetan Annals (PT 1288, IOL Tib J 750, Or.8210/187), a context in which one expects to find it, if it enjoyed such a prominent role as Macdonald supposes. If attention turns from a discussion of which texts do or do not contain the word sku bla and to a discussion of how the term sku bla is used, the information about the ritual gathered from these texts indeed yields an explanation for its absence from the Old Tibetan Annals.

\section{Date of the ceremony}

In three Dunhuang documents attention is drawn to the date of the propitiation of the sku bla. In the Annals of 'A zha Principality (IOL Tib J 1368), the rite is described with the phrase lo sar dang dbyar sla ra ba'i sku bla ched po gsol 'they offered the great $s k u$ bla of the New Year and the first summer month' and similar expressions (IOL Tib J 1368, 11. 05, 21, 31, 36, 47, 50). These passages make clear that the sku bla was a large and regularly occurring event associated with certain times of the year, in particular the New Year, the first summer month, and the first winter month. In the Shangshu paraphrase (PT 0986) the climactic sacrificial rites, including to the $s k u$ bla, are offered in the first month of summer (dbyar sla ra ba, 1. 106); this detail is not simply a translation of the Chinese text, but an innovation. ${ }^{11}$ The sku bla rites must have been strongly associated with specific times of performance for the date of its celebration to find its way as an innovation into an adaptation of a Chinese text. The timing of the ceremony described in the Annals of 'A zha Principality (IOL Tib J 1368) and the Shangshu paraphrase (PT 986) is further corroborated in the Dunhuang document PT 2204c, apparently overlooked by Macdonald and Stein. An administrative text handling the confiscation of provisions from rebels, PT 2204c makes reference to the sku bla as a means of dating other events: sla ra ba'i ngo la mo drus gi sku bla gsol ba'i tshe // 'when the sku bla of mo drus (?) was celebrated at the start of the first month' (1. 16). The great majority of administrative documents discovered at Dunhuang describe events which took place in that region. Thus, this text can be understood to demonstrate that the sku bla cult was also propitiated in the region around Dunhuang and thereby suggests that the sku bla rites were performed outside of 'A zha. Thus there are three texts, the Annals of 'A zha Principality (IOL Tib J 1368), the Shangshu paraphrase (PT 0986), and PT 2204c, which all agree that

11 W. South Coblin, "A Study of the Old Tibetan Shangshu Paraphrase," Journal of the American Oriental Society 111.3 (1991): 538. 
the sku bla was celebrated in the first month (of either winter or summer). ${ }^{12}$ Rather than the presence of the sku bla in the Shangshu paraphrase pointing to a Chinese origin of the $s k u$ bla, as Stein suggests, it indicates the pervasiveness of the sku bla cult in the Tibetan cultural region at the time.

\section{Purpose of the ceremony}

The most informative text for determining the purpose and context of the sku bla rite is the The envoys of Phywa to Dmu (PT 126), which serves as an etiological myth for this ritual. The envoys of Phywa ${ }^{13}$ explain quite clearly their two related goals in visiting the court of Dmu. The first 'is dga' ni lha byed 'in order to revere the joyous god' (1. 113) and sku bla la yon 'bul 'to offer a gift to the sku bla' (11. 124-125) of the lord of Dmu. The second is to convince the lord of Dmu to descend to the earth on behalf of man: in the words of their lord's commission to them "mgo nag 'greng la rje myed rje skos la [for the upright and black-headed who have no lord, appoint a lord!]" (11. 111-112). The articulation of these two goals makes explicit the link between the sku bla rite and the myth of Gnya' khri Bstan po, the legitimizing narrative for Tibetan kingship, whereby the royal clan is descended from the gods, reluctantly come to earth out of compassion to rule over mankind. ${ }^{14}$

After considerable hesitation the lord of Dmu does allow the envoys of Phywa to propitiate the sku bla. At this juncture the Dmu and Phywa establish a bond of fictive kinship signaled by the switch in the discourse of the lord of Dmu addressing the envoys of Phywa from the exclusive pronoun nged to the inclusive pronoun ' $o$ skol at line 165, and such explicit statements as "khyed 'o skol la dbyar myed pas [there is no difference between you and us]" (1. 167). One can link the two goals of the envoys of Phywa by regarding the sku bla ceremony as a confirmation of the relationship between the emperor and his vassals, where the lord of Dmu is an analog to the Tibetan emperor and the envoys of Phywa are analogs to the emperor's willing vassals.

12 A yul-lha ceremony in Ladakh shares several features with the sku bla ceremony (see Nathan W. Hill, "A new interpretation of the mythological incipit of the Rkong po inscription," in Tibetan Inscriptions: Proceedings of a Panel Held at the Twelfth Seminar of the International Association for Tibetan Studies, Vancouver 2010, ed. Kurt Tropper and Cristina Scherrer-Schaub [Leiden: Brill, 2013], 180, and note 20 below), but has rather different timing; the Ladakhi villagers "regularly pay homage to the yul lha; at New Year (lo gsar) around the time of the winter solstice, in midsummer, and at the occasion of srub lha, 'first crops to the gods', which initiates the harvest", Pascale Dollfus, "No sacred mountains in Central Ladakh?" in Reflections of the Mountain: Essays on the History and Social Meaning of the Mountain Cult in Tibet and the Himalaya, ed. Anne-Marie Blondeau and Ernst Steinkellner (Vienna: Verlag der Österreichischen Akademie der Wissenschaften, 1996), 10.

13 On the Phywa and many other phenomena relevant to the study of the sku bla and PT 0126 see Toni Huber, "The Iconography of gShen Priests in the Ethnographic Context of the Extended Eastern Himalayas, and Reflections on the Development of Bon Religion," in Nepalica-Tibetica. Festgabe for Christoph Cüppers, vol. 1, ed. Franz-Karl Ehrhard and Petra Maurer (Andiast: International Institute for Tibetan and Buddhist Studies, 2013), 263-94.

14 See Samten Karmay "The Origin Myths of the First King of Tibet as Revealed in the Can lnga," in Tibetan Studies, vol. 1, ed. Per Kværne (Oslo: The institute for Comparative Research in Human Culture, 1994), 408-29, and Nathan W. Hill, "Come as lord of the black-headed: an Old Tibetan mythic formula," in Tibet after Empire Culture, Society and Religion between 850-1000, ed. Christoph Cüppers et al. (Lumbini: Lumbini International Research Institute 2013), 169-79. 
The Rkong po Inscription makes clear that for the king of Rkong po, like for the envoys of Phywa, the sku bla rite establishes a relationship of vassalage to the Tibetan imperial family: "Kar po nü / thog ma yas gshegs pa'̌ tshe // mched gnyı̌s kyi / sku bla gnyan po gsol ba dang [Kar-po, from when he first arrived from above propitiated the fierce(?) sku bla of the two brothers]". ${ }^{15}$ The sku bla is the spiritual proxy of the Tibetan emperor, and propitiating the cult of the sku bla spiritually binds a person as a vassal to the emperor. ${ }^{16}$

That the sku bla is particularly tied to the fate of the emperor and his court is further confirmed in the mo divination text PT 1047. In its current form the text has six sections. Each section concerns the category of individual for whom divinations of a particular type are relevant. These six sections present a stratified social hierarchy. The first section deals with divination king, royal family and ministers. The second relates to commoners. The third section treats the fate of lower class people and animals. The last three sections deal with enemies and maleficent divinities. The $s k u$ bla is mentioned only in the first section. ${ }^{17}$

In terms of social hierarchy the sku bla sits as the spiritual parallel of the Tibetan emperor at the head of the great chain of being which rationalised the imperial Tibetan universe. In an edict of Khri Gtsug lde brtsan in the Prayers for the foundation of De ga g.yu tshal monastery (PT 16), the sku bla sits at the head of a list of divine beings and natural forces: sku bla ring rdzi dang / gnam sa'i lha klu / thams chad kyang 'go zhing dgyes // "all the sku bla ring, wind, and gods and serpents $(k l u)$ of heaven and earth did 'go and rejoiced" (folio 36 recto, 1. 4). Just as the envoys of Phywa become as kin to the lord of Dmu through the cult of the sku bla, so the vassals of the Tibetan emperor would have confirmed their feudal bond to the emperor with the same ceremony. For the envoys of Phywa the sku bla cult serves as a prerequisite for the lord of Dmu descending to the earth as ruler of men. In the reenactment of this myth the vassals of the Tibetan emperor would have been reminded that the Tibetan emperor ruled as the heaven-sent lord of all mankind. ${ }^{18}$

In a passage that takes up the narrative of divine descent immediately after the arrival on earth, the Prayers for the foundation of De ga g.yu tshal monastery (PT 16)

15 Iwao Kazushi, et al., Old Tibetan inscriptions (Tokyo: Research Institute for Languages and Cultures of Asia and Africa, Tokyo University of Foreign Studies, 2009), 15, 1. 6. This article transliterates the Old Tibetan gi gu inversé using " $l$ " rather than the capital "I" of Iwao, et al.

16 In most interpretations of the Rkong po Inscription Dri gum btsan po's older son, Nya-khyi, who is identified with Kar po, propitiates the shared sku bla of himself and his younger brother Sha-khyi, cf. Hugh Richardson, "The rKong-po Inscription," Journal of the Royal Asiatic Society of Great Britain and Ireland 104.1 (New Series): 38; Chen Jian 踐陳 and Wang Yao 王堯, Bod kyi rdo ring yi ge dang dril bu'i kha byang (Beijing: Mi rigs Dpe skrun khang, 1984), 80; id. Bod kyi gnah rabs yig cha gces btus (Chengdu: Si khron Mi rigs Dpe skrun khang, 2003), 66-67, 72; Li Fangkuei and W. South Coblin, A Study of the Old Tibetan Inscriptions (Taipei: Institute of History and Philology, Academia Sinica, 1987), 211, 215; Bkra shis zla ba, "Rkong po g.yung drung 'dzin gyi rdo brkos yi ge'i ma phyi dngos dang de 'dra bshus byas rigs 'ga' zhig gi gshib bsdur (A Comparison of the Actual Original Text of the Rkong po Rock Inscription with Some Copies Made of it)", Bod ljongs zhib "jug 2004 (4), 16. In contrast, I propose that Kar po and Nya khyi are not the same figure. See Hill "mythological incipit," 171-82.

17 Macdonald, "Une lecture," 271, 276-77.

18 The Rkong-po Inscription makes clear that this ritual observance can be dangerous to human life:

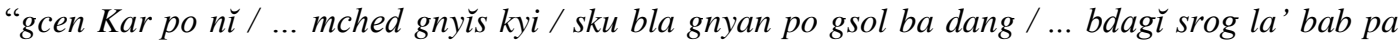
man chad ky̆ cho gar mdzad pa / srog phongs ma bgyı̌s te / / [the elder brother Kar-po ... propitiated the fierce $s k u$ bla of the two brothers ... he performed ceremonies which endangered his life, he was not sparing of life]", Iwao et al., Old Tibetan inscriptions, 15, 11. 6-7. 
also presents a close association between the first Tibetan emperor and the sku bla: ' $O$

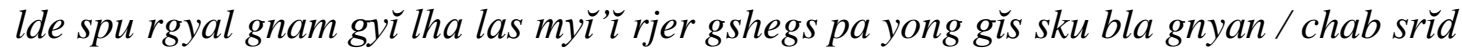
che / chos bzang/ [When 'O lde spu rgyal came from among the gods of heaven as lord of men, his sku bla was strong, his government great, his customs good] (folio 35 verso, 1. 2). Like in The envoys of Phywa to Dmu (PT 126), here the sku bla is closely associated with the descent of the first Tibetan emperor from heaven. Because the Prayers for the foundation of De ga g.yu tshal monastery (PT 16) was composed in celebration of a treaty between China and Tibet, Stein points to this text as a piece of evidence in support of the idea that the sku bla rite is a Chinese import. However, an examination of those locations at which the sku bla is invoked in the text reveals the sku bla in a telling of the narrative of divine descent laden with traditional diction and formulae, ${ }^{19}$ consistent with the presentation of the $s k u$ bla in texts free of the suspicion of Chinese influence.

An obvious suggestion for why observance of the sku bla rite is lacking in the Old Tibetan Annals (PT 1288, IOL Tib J 750) is that the sku bla is a ritual performed exclusively by vassals of the empire and not by the central government. This interpretation of the evidence is consistent with the ceremony as described in The envoys of Phywa to Dmu (PT 126). The envoys, who are to be enfeoffed, wish to perform the rite; the lord himself appears not to perform the sku bla rite, but rather only reluctantly authorizes its performance. It is fitting that outlying areas such as 'A zha, Rkong po, and Dunhuang should ritually reinforce their submission to the Tibetan state in a regularly scheduled grandiose ceremony. But it would be odd for the Tibetan emperor to pay ritual obeisance to his deified persona. Consequently, the Old Tibetan Annals (PT 1288, IOL Tib J 750), which describes the official goings on of the emperor and his kith and kin, omits mention of the sku bla rite because he and his government did not perform it. ${ }^{20}$

The sku bla ceremony is no peripheral foreign borrowing into Tibet, but a central part of the ideology of sacral kingship in the Tibetan Empire. The ceremony created a bond of vassalage between the celebrant and the person of the Tibetan emperor in his role as deified ruler. This ceremony was not performed by the royal court itself, but was rather performed by vassals of the emperor. The theory elaborated here, agreeing in essence with the findings of Macdonald, not only gives account for the absence of the sku bla from the Old Tibetan Annals and its presence in the Annals of 'A zha Principality (IOL Tib J 1368), the Envoys of Phywa to Dmu (PT 126), the Rkong po Inscription, and other Dunhuang texts such as PT 1047 and PT $2204 \mathrm{c}$, but also better accounts for the use of sku bla in the two texts, the Shangshu paraphrase (PT 986) and the Prayers for the foundation of De ga g.yu tshal monastery (PT 16), than does the vague specter of Chinese influence invoked by Stein.

\section{4 sku bla and sku-lha: is the sku bla a mountain deity?}

Stein, summing up and endorsing the research of Macdonald, remarks that sku bla

19 Hill, "Come as lord of the black-headed," 169-71.

20 This portrait of the sku bla can be further confirmed with reference to the anthropological literature. In Ladakh there is a ceremony which may well be cognate to the sku bla rite, in which the officiant called lha bdag pa is a hereditary "royal representative and master of the cult"; Dollfus, "No sacred mountains," 10. Like the sku bla rite, this ceremony shows subjugation to royal authority. 
"sont des divinités, souvent des montagnes sacrées, considérées comme les ancêtres des rois qui les protègent [are divinities, often of sacred mountains, considered as the ancestors of the kings who protect them]". ${ }^{21}$ To me the evidence is insufficient to conclude that in the period of the Tibetan Empire there was more than one sku bla, or that the sku bla was a mountain deity. ${ }^{22}$ As Walter writes "we have not a single text relating a 'mountain cult' or its rituals, or references to them, in Old Tibetan literature". ${ }^{23}$ Macdonald's argument for both of these claims takes as its point of departure that the phrase sku bla De mo in line 6 of the Rkong po Inscription is a single noun phrase, i.e. that De mo is a sku bla. She continues to demonstrate with reference to a number of texts that De mo is a mountain deity in Rkong po. ${ }^{24}$ While there can be no disagreement that De mo is a mountain deity in Rkong po, I have argued following the analysis of Uebach that the phrase sku bla De mo in line 6 of the Rkong po Inscription must be analyzed as two separate nouns. ${ }^{25}$ The analysis of the phrase sku bla De mo as one noun phrase leads Macdonald to conclude both that there are multiple sku bla and that sku bla are mountain deities. Among the Old Tibetan documents consulted here the only evidence of any sku bla other than that of the Tibetan imperial family comes from Shangshu paraphrase (PT 986). Since this text is a paraphrase of a Chinese original it is necessarily speaking of foreign divinities. For the purposes of translation the sku bla has been identified with the tiandishen 天地神 'gods of sky and earth' and mingguishen 明鬼神 'type of spirits' Chinese divinities, of which there can be a plurality. The Old Tibetan evidence examined here and in previous scholarship does not conclusively point to a plurality of sku bla, and many attestations of the word sku bla refer to the same unique entity.

Subsequent to the identification of De mo as a sku bla, the remainder of Macdonald's argument that the sku bla are mountain deities relies on the identification of the term sku bla with the term $s k u l h a$, which unambiguously refers to mountain deities in a number of post-dynastic texts. ${ }^{26}$ Why the $s k u$ lha of the late sources can be identified with sku bla of the earlier sources is a question Macdonald does not discuss. In Old Tibetan the syllables bla and lha were certainly distinct, as their reflexes remain in all contemporary Tibetan dialects.

If the phonological incongruence of sku bla and sku lha were somehow inadequate to demonstrate the non-identity of these terms, this can be further confirmed through their contrasting use in Dpa'o gtsug lag 'phreng ba's Mkhas pa'i dga' ston. In his paraphrase of the Sino-Tibetan treaty inscription, Dpaho lists the $s k u$ bla (and not the sku lha) among the divine and celestial witnesses. ${ }^{27}$ The term sku-lha in contrast occurs in his quotation from the pro-Buddhist edict of Khri Srong lde

21 Stein, "Tibetica Antiqua I," 200.

22 It may be that examination of further Old Tibetan documents will require the postulation of a multitude of sku bla; the point here is simply that the evidence discussed by Stein and MacDonald does not lead to this conclusion.

23 Michael Walter, Buddhism and Empire: the Political and Religious Culture of Early Tibet (Leiden: Brill, 2009), 230-31, also cf. 105, 230-40. Although I fully accept Walter's conclusion that the $s k u$ bla are not mountain deities, I disagree with his suggestion that they are human beings. See Nathan W. Hill, "Buddhism and Empire. By Michael Walter. pp. xxvii, 311. Leiden, Brill, 2009," Journal of the Royal Asiatic Society of Great Britain \& Ireland (Third Series), 20.4 (2010): 559-62.

24 Macdonald "Une lecture," 299.

25 Helga Uebach, Ein Beitrag zur Dokumentation der Inschrift von rKon்-po, (Sankt Augustin: VGH Wissenschaftsverlag, 1985), 67, n. 98; Hill "mythological incipit," 178.

26 Macdonald "Une lecture," 299-300.

27 Stein, “Tibetica Antiqua I": 204, citing volume ja, folio 132a. 
brtsan (r. 755-797): de na Bod kyi chos rnying pa ma lags-la / sku lha gsol ba dang cho ga myi mtun pas / kun kyang ma legs su dogs te [At that time some people followed the bad practices of the old religion of Tibet, and were addicted to all sorts of bad actions such as worshipping the personal gods (sku-lha) and using improper rites]. ${ }^{28}$ If as Richardson suggests $s k u$-lha in this passage were to be identified with $s k u b l a,{ }^{29}$ then Khri Srong lde brtsan would be condemning a ritual practice whose sole purpose was the perpetuation and the deification of his own status. Even if Khri Srong lde brtsan were such a poor pragmatist as to decide that a cult specifically built around legitimizing his own reign was a deplorable anti-Buddhist activity which needed to be suppressed, this would render the prominent role of the sku bla cult in the petition of the Rkong po king to this very emperor ridiculous. Surely the rulers of Rkong po would not have been so foolish as to invoke their devotion to a hated heathen cult in their petition for tax relief to an emperor with a specific agenda to suppress this cult. On the basis of the contrast between sku bla gsol in Dpa'o gtsug lag 'phreng-ba's paraphrase of the Sino-Tibetan treaty inscription edict and sku-lha gsol in his record of Khri Srong lde brtsan's edict one may conclude that sku bla gsol and sku-lha gsol are two quite different activities, and that Macdonald's theory that $s k u$ bla are mountain deities is built on an untenable axiom. ${ }^{30}$

Setting aside the meaning of sku lha and its possible relationship to sku bla, one can conclude that the sku bla are not mountain deities because the Shangshu paraphrase (PT 986) specifically contrasts sku bla and mountains: chab 'og du 'duspa' sku bla 'o 'tshal dang / ri gnyan po dang / chu chen po la stsogs pa / ril mchod de [he sacrificed to all the sku bla who had gathered under his control, and to the mighty mountains, the great rivers and so on] (11. 109-110). ${ }^{1}$ This passage shows a plurality of sku bla, but because the cultural context is Chinese the presentation of multiple $s k u$ bla in this text does not imply a multiplicity of sku bla in Tibetan tradition. Similarly, the use of the English word 'gods' to describe non-Judeo-Christian traditions in no way suggests that the (traditionally) Christian English are polytheists. As a final point militating against sku bla as mountain deities is the realization that in the Envoys of Phywa to Dmu (PT 126) the lord of Dmu has his sku bla with him up in heaven, and unless there are mountains in heaven, and these mountains are transportable down to earth, this sku bla could not have been a mountain deity. Macdonald's understanding of the sku bla as mountain deities relies on her analysis of sku bla De mo as one noun phrase and her identification of sku bla with sku lha, both of which are false. A clear distinction between the sku bla and mountains, on the one hand, and the sku bla and sku lha, on the other hand, are found in Old Tibetan texts and in their quotation or paraphrase by Dpa'o gtsug lag 'phreng ba. There is one sku bla and it is not a

28 Hugh Richardson, High Peaks, Pure Earth: Collected Writings on Tibetan History and Culture (London: Serindia, 1998), 93, 97.

29 Ibid., 99 note 11.

30 Walter translates the passage in question radically differently from Richardson: "At this point, excepting the old Tibetan chos, all [other] rituals at all, because they were rituals not in accord with the sku lha gsol ba ..., were considered not to be good", Walter, Buddhism and Empire, 72, n. 84, brackets in original, ellipsis mine. Walter does see the word sku lha here as a mistake for sku bla, but emphasizes that there is no reason to think that the passage involves mountain deities. There are two problems with Walter's translation: one is that ma lags does not mean 'except for'; the other is that is the interpretation of the phrase sku lha gsol ba dang cho ga myi mtun pas. Richardson sees dang as coordinating two noun phrases, Walter sees it as governed by the verb mtun. However, the word order necessary for Walter's interpretation would be cho ga sku lha gsol ba dang myi mtun pa. 
mountain deity.

The sku bla of the two sons of Dri gum btsan po is the same sku bla that the envoys of Phywa ask to worship, the sku bla that was celebrated in 'A zha and Dunhuang, the sku bla of the imperial family; this sku bla bred with De mo and begat a god worshiped by the kings of Rkong po. The evidence of the sku bla across Old Tibetan literature indicates that the sku bla is the spiritual counterpart of the Tibetan emperor and has been his companion ever since both resided in the heavens, specifically the realm of Dmu; vassals of the Tibetan Empire (not the imperial government itself) propitiate the sku bla in ritual observance. 